\title{
UMA ALTERNATIVA DE TRABALHO: LÍRICA E LIRISMOS NA LITERATURA BRASILEIRA
}

\section{Andrea Ad Reginatto}

\author{
Por tanto amor, por tanta emoção, \\ A vida me fez assim: \\ Doce ou atroz, manso ou feroz, \\ Eu, caçador de mim. \\ Preso a canções, \\ Entregue a paixões que nunca tiveram fim, \\ Vou-me encontrar longe do meu lugar. \\ Eu, caçador de mim \\ (Milton Nascimento)
}

Todas as obras literárias, de acordo com seu conteúdo e estrutura, pertencem, normalmente, a um dos gêneros literários fundamentais: lírico, narrativo e dramático.

O presente estudo, busca elucidar questões relativas à lírica e, para tanto, abordará alguns conceitos importantes para o entendimento do fenômeno poético.

Afinal, o que é lírica?

Conforme Rogel Samuel, a palavra lírica deriva do grego lyrikós, que significa algo que concerne à "lira", ou o som proveniente da lira, um instrumento musical primitivo de cordas.

No passado, na antigüidade clássica, a poesia era "cantada" e, muitas vezes, ligada a situações que envolviam alegria ou tristeza, como por exemplo, o ato de cantar para um bebê dormir ou, até mesmo a morte de alguém.

Segundo Salvatore D'Onofrio, na época do romantismo, o gênero lírico alcança sua maior relevância, identificando-se com o próprio conceito de poesia, no seu sentido estrito. Para ele, Goethe, Lamartine e Poe são exemplos de poetas de primeira linha, que iniciam um filão de lirismo intimista, que influenciará marcadamente a poesia simbolista e modernista.

A partir das definições trabalhadas, pode-se chamar de texto lírico toda produção em que há predominância da expressão individual do "eu", através de uma linguagem bem elaborada, sobretudo no ritmo e nas imagens. Insere-se, neste tópico, a utilização de recursos sonoros e textuais, tais como: rima, métrica, figuras de linguagem, etc. 
O texto lírico pode aparecer em verso ou em prosa. Quando for em verso, encaixam-se nessa classificação as formas poéticas com estrutura fixa, como o soneto (composição poética de 14 versos distribuídos em dois quartetos e dois terceto e apresenta sempre métrica exata, com versos alexandrinos), e as espécies literárias que se definem como líricas: elegia ( poesia lírica em tom triste, cujo tema central é ligado à morte de um ser amado) e cantiga ( poema com versos curtos, normalmente redondilha).

Ao contrário do texto narrativo, a produção lírica não apresenta narrador, nem personagens e, também, não conta uma história. A seguir, alguns exemplos de lírica em versos:

A DECISÃO
Cansei de amor de brinquedo
Eu quero amor de verdade
Quero sentir que a saudade
Está judiando de mim.
Não quero dizer amor com o coração sossegado
Quero pecar sem pecado
E andar sorrindo sozinho
Até que falem de mim
Talvez me chamem de louco
Esta loucura eu desejo
Eu quero amor de verdade
Cansei de amor de brinquedo.
(Prado Veppo)

Luiz Guilherme do Prado Veppo nasceu em Porto Alegre, mas considerou-se santa-mariense de coração. Formou-se em Medicina pela UFSM, dedicou- se à psiquiatria e à literatura e representa um nome expressivo na produção poética santamariense. Escreveu vários livros de poesias entre eles Alba Tempo e Rosa (1962) Passos do vislumbre (1993) e Girassol azul (1990). O texto citado apresenta inúmeras características da poesia lírica, a começar pelas marcas verbais em primeira pessoa que aparecem já no primeiro e no segundo verso: "cansei" e "quero". Isso leva o leitor a pensar que o sujeito lírico está presente com seus sentimentos no texto. Além das marcas verbais, há, também, os pronomes pessoais "eu/mim/me" que reforçam esta alternativa de pensamento. Como se não bastasse, existe ainda no texto a temática predominante - o amor - mais uma evidência de que o texto é uma forma lírica.

A atividade artística de Prado Veppo coincide com as produções brasileiras que renovam a lírica e propagam-se em tendências diversas, como a busca do 
despojamento expressivo, o neovanguardismo e o engajamento político-ideológico do verso. Assim, o traço principal de sua obra fica por conta de um estilo metafísico que se assenta em termos conceituais. As definições sobre o prosaico, natureza e transcendente, dão à construção de Veppo um substrato positivista, que nasce pela alquimia das palavras, misturando significantes diversos e, às vezes, conflitantes, na busca do sentido inaudito e sintetizador. Daí as constantes variações sobre o mesmo tema, a fuga das imagens grandiosas e das construções longas.

Casimiro de Abreu, poeta que pertence a uma das gerações do romantismo brasileiro, também é um exemplo de escritor lírico. O lirismo intimista criado por escritores europeus é bem representado no Brasil através dos versos desse escritor. A poesia de visão pessoal sobre o tema da infância é a tônica do fragmento a seguir citado:

\footnotetext{
Oh! Que saudades que tenho

Da aurora da minha vida

Da minha infância querida

Que os anos não trazem mais!

Que amor, que sonhos, que flores

Naquelas tardes fagueiras

À sombra das bananeiras

Debaixo dos laranjais!

(...)
}

As marcas verbais e os recursos de métricas e rima colocam ao leitor a idéia do projeto romântico - a idealização do passado e, conseqüentemente, a saudade da infância que ficou para trás, com tudo de belo e formoso.

Vê-se, através dos dois textos trabalhados, que o importante ao trabalhar lírica não é somente a compreensão do sentido do texto, pois a conexão lógica acaba sendo colocada em segundo plano, a fim de dar espaço à comunicação entre leitor e poema; assim, primeiro o leitor se emociona, para depois entender. Emil Staiger afirma que para a insinuação ser eficaz, o leitor precisa estar indefeso, receptivo e isso só ocorre quando há sintonia entre leitor e poeta.

À medida que se trabalha muito com sujeito lírico é preciso lembrar que este não deve ser confundido com o eu biográfico do autor, pois este está ligado comprometidamente com os fatos do mundo exterior, enquanto o outro apenas se deixa levar pela imaginação e pelos mistérios que a cercam. 
Mario Quintana é outro nome que pode ser identificado na produção lírica. Nascido em Alegrete, adotou Porto Alegre como sua cidade natal e é, justamente, da relação que o poeta estabelece com a cidade que nascem alguns de seus versos, como os que seguem:

\author{
O MAPA \\ Olho o mapa da cidade \\ Como quem examinasse \\ A anatomia de um corpo... \\ (É que nem que fosse o meu corpo) \\ Sinto uma dor infinita \\ Das ruas de Porto Alegre \\ Onde jamais passarei... \\ Há tanta esquina esquisita, \\ Tanta nuança de paredes, \\ Há tanta moça bonita \\ Nas ruas que não andei \\ ( $E$ há uma rua encantada \\ Que nem em sonho sonhei...) \\ Quando eu for, um dia desses, \\ Poeira ou folha levada \\ No vento da madrugada, \\ Serei um pouco do nada \\ Invisível, delicioso \\ Que faz com que o teu ar \\ Pareça mais um olhar, \\ Suave mistério amoroso, \\ Cidade do meu andar \\ (deste já tão longo andar!) \\ E talvez de meu repouso.
}

Em O mapa, poema que faz parte do livro Apontamentos de história sobrenatural (1976), encontra-se um sujeito lírico debruçado sobre a cidade, no caso Porto Alegre. Mario Quintana adotou-a e, muitas vezes, revelou-a em seus versos, mas sempre de maneira compungida, como é possível observar no poema em questão. A manutenção de uma lírica tradicional é contrabalançada por uma linguagem de absoluta simplicidade, como se houvesse a fusão do subjetivismo crepuscular - de inspiração simbolista com o estilo coloquial da poesia moderna. Há, no poema, uma relação do sujeito lírico com a cidade e inúmeras metáforas indicam o caminho para temas como a velhice e a morte como mostram os versos abaixo: 
Quando eu for um dia desses, poeira ou folha levada (...)

(...)

Cidade do meu andar

Deste já longo andar!

E talvez do meu repouso

A presença das formas verbais em primeira pessoa e dos pronomes pessoais reiteram as características do gênero lírico: Olho / meu / sinto / passarei / andei / sonhei / eu / serei / meu.

\author{
XIII \\ Da vez primeira que me assassinaram \\ Perdi um jeito de sorrir que eu tinha... \\ Depois, de cada vez que me mataram, \\ Foram levando qualquer coisa minha \\ E hoje, dos meus cadáveres, eu sou \\ O mais desnudo, o que não tem mais nada... \\ Arde um toco de vela, amarelada... \\ Como o único bem que me ficou! \\ Vinde, corvos, chacais, ladrões de estrada! \\ Ah! Desta mão, avaramente adunca, \\ Ninguém há de arrancar-me a luz sagrada! \\ Aves da noite! Asas do Horror! Voejai! \\ Que a luz, trêmula e triste como um ai, \\ A luz do morto não se apaga nunca!
}

A produção poética de Mario Quintana se inscreve entre a analogia e a ironia, entre o sublime e o prosaico. Assim, o poema transcrito, XIII, inserido no livro A rua dos cataventos (1940), que reúne um conjunto de 35 sonetos é uma inusitada construção, pois a forma possui vínculos com as estéticas do passado (simbolista e parnasiana).

As marcas verbais em primeira pessoa (perdi, tinha) e os pronomes (me, eu) evidenciam a presença do subjetivismo, característico do texto lírico. Os versos de Quintana revelam os sentimentos do sujeito poético que podem ser traduzidos pelas sucessivas perdas. Através dos assassinatos figurados e constantes o sujeito lírico vai perdendo suas características, chegando a ter semelhanças com um cadáver. No segundo quarteto o sujeito lírico aparece como um cadáver definitivo: $E$ hoje, dos meus cadáveres..., ao qual só restou um bem: o mais desnudo, o que não tem mais nada...arde um toco de vela amarelada... como o único bem que me ficou. $O$ adjetivo 
amarelada remete o leitor a algo antigo - entende-se que a morte e a velhice estão entre os sentimentos do sujeito poético. Os vocativos expressos no primeiro terceto do poema convocam aqueles que deveriam consumir seus restos mortais e a vela acesa nas mãos, permite que a luz não se apague. A imagem da luz, simbolizada pela vela, pode ser entendida como a representação da poesia, o último bem que resta após uma sucessão de perdas.

Outra forma lírica escrita por Quintana está no livro Espelho Mágico (1951) - pouco trabalhado pela crítica que o considerou passadista ao ser comparado aos poemas de versos livres - que traz por epígrafe um versículo do Eclesiastes: Não sejais muito justo; nem mais sábio do que é necessário para que não venhas a ser estúpido. 0 primeiro quarteto é:

\section{DA OBSERVAÇÃO}

Não te irrites, por mais que te fizerem...

Estuda, a frio, o coração alheio.

Farás., assim, do mal que eles te querem,

Teu mais amável e sutil recreio.

No poema, composto por quatro versos, o poeta aconselha o leitor a não se aborrecer com as maldades alheias fazendo um convite: observar as pessoas de modo frio e sem paixão, pois assim se pode perceber o mundo como espetáculo. $O$ livro é recheado de ironia e humor, captando os pequenos e grandes defeitos do ser humano, além de vícios e maldades que são comuns nas relações interpessoais, porém mais do que ensinar algo sobre a vida, existe a busca do divertimento, do jogo lúdico entre as palavras, da sonoridade expressada através das rimas.

Segundo Regina Zilberman, ao longo da trajetória literária, Mario Quintana mostra forte unidade de tema, centrado na problemática individual. Atribuindo à existência enquanto temporalidade a razão do desconforto perante a realidade, examina esta última negativamente, rejeitando tudo que diga respeito a uma presença física. Decorre daí a presença forte da infância como motivo para a criação poética, tal como acontece com Casimiro de Abreu no poema infância.

Mario Quintana, poeta contemporâneo, assume em seus versos uma certa influência do nostalgismo romântico e simbolista, configurando-se, desse modo, como um escritor basicamente lírico na produção escrita. 
Trabalhar poesia lírica na escola não é tarefa fácil, pois sabe-se que a literatura concorre diretamente com tantos outros meios de comunicação verbal e visual de maior estímulo e atração para os jovens. No entanto, é preciso lembrar antes de tudo que a literatura, e somente ela, propiciam uma redescoberta do eu. É a partir do ato solitário, do prazer com que se trabalha o texto que, muitas vezes, o homem desvenda segredos e enigmas da vida tão corrida nos dias atuais. Utilizar o texto poético como motivo para uma aula de português pode, por exemplo, tornar menos cansativo o conteúdo sobre verbos, aproveitando as marcas verbais apresentadas nos poemas aqui trabalhados.

Por fim, para trabalhar o texto lírico, hoje, além do material tradicional, existem no mercado CDs que possibilitam aliar o texto escrito a uma forma lúdica - a música. Os poemas de Mario Quintana foram, recentemente, editados em forma de CD e podem servir como instrumento de trabalho aos professores auxiliando, desse modo, no processo de aprendizagem e, mais do que isso possibilitando e desenvolvendo nos alunos o gosto pela leitura, particularmente, pela poesia, tão renegada nos dias atuais dentro do universo escolar.

\section{BIBLIOGRAFIA}

ABREU, Casimiro. Poesias. Rio de Janeiro: Agir, 1979.

D'ONOFRIO, Salvatore. Literatura Ocidental. São Paulo: Ática, 2000.

SAMUEL, Rogel. Manual de teoria literária. Petrópolis: Vozes, 1990.

STAIGER, Emil. Conceitos fundamentais de poética. Rio de Janeiro: Tempo Brasileiro, 1975.

QUINTANA, Mario. Apontamentos de história sobrenatural. Porto Alegre: Globo, 1976.

Poesias. Reunião de: A rua dos cataventos, Canções, Sapato

florido, Espelho mágico, Aprendiz de feiticeiro. Porto Alegre: Globo, 1962.

VEPPO, Luiz Guilherme do Prado. Girassol Azul. Santa Maria: Pallotti, 1996.

ZILBERMAN, Regina. A literatura no Rio Grande do Sul. Porto Alegre: Mercado Aberto, 1992. 